\title{
Informação e conhecimento na nova ordem mundial
}

Helena M. M. Lastres

\section{Resumo}

Este artigo discute o papel da informação e do conhecimento na nova ordem mundial. O foco central é o advento e a difusão da denominada economia da informação e do conhecimento, a qual vem induzindo novas atividades, conceitos de competitividade, estratégias organizacionais e formatos institucionais (que influenciam empresas, centros de ensino e pesquisa, governos etc. e até os próprios indivíduos) e exigindo novas capacitações.

\section{Palavras-chave}

Economia e sociedade da informação e do conhecimento; Tecnologias da informação; Informação e estratégias competitivas.

\section{INTRODUÇÃO}

$\mathrm{Na}$ década de 80 , o cenário mundial sofreu significativas transformações tecnológicas, organizacionais, geopolíticas, informacionais, comerciais e financeiras, institucionais, culturais, sociais inter-relacionadas. Objetivando entender as particularidades da nova ordem mundial em conformação, autores de diferentes áreas vêm cunhando designações e desenvolvendo formas de categorizá-la. Tais esforços tendem sempre a refletir as próprias preocupações e enfoques particulares das áreas a que tais autores pertencem. A diversidade da caracterização e interpretação desta nova ordem é proporcional à variedade de abordagens de autores de diferentes áreas. Assim, economistas vêm dando maior destaque à dimensão econômica, sociólogos à social e assim por diante. Como decorrência, também diversas designações e descrições têm sido utilizadas para caracterizar a atual nova ordem mundial, as quais têm sido impregnadas por tais influências. Dentre outras, destacamse as seguintes: Era, Economia ou Sociedade da Informação ou do Conhecimento.

Este artigo parte do argumento de que, para melhor apreender a essência e alcance das atuais transformações, mostra-se oportuno conhecer como autores, utilizando diferentes abordagens teórico-conceituais, vêm discutindo a importância da informação e do conhecimento na nova ordem em conformação. Portanto, mesmo centrando a discussão nas características econômicas da nova era, a discussão aqui proposta visou a fazer uso da contribuição de autores de diferentes áreas do conhecimento, tais como economia, ciência da informação, comunicações, história, sociologia, filosofia, engenharia e geografia.
O artigo encontra-se estruturado da seguinte forma:

- a primeira seção analisa a denominada revolução da informação e do conhecimento como marco de uma nova etapa de acumulação econômica;

- a segunda aprofunda tal discussão, examinando a conformação da economia da informação e do conhecimento e visando a identificar e discutir suas principais características;

- a terceira analisa algumas das principais estratégias e formatos organizacionais associados à atual era, enfatizando particularmente a importância da capacitação de recursos humanos como base do processo de criação e acumulação de conhecimentos para real aproveitamento das oportunidades disponibilizadas pela acelerada difusão das novas tecnologias;

- a última encerra a discussão destacando a importância de enfoques multidisciplinares e fusão de conhecimentos para melhor apreender a abrangência e as características das transformações em curso.

\section{Revolução da informação e do conhecimento}

Grande parte das análises objetivando entender e caracterizar a nova ordem mundial ressalta, por um lado, 0 esgotamento do padrão de acumulação anterior e, por outro lado, o advento (e rápida difusão) de um novo padrão criando novas possibilidades de crescimento. Dentre outros, Harvey $^{1}$, ao discutir as origens de tais transformações, aponta para a necessidade de entender tal processo dentro de um quadro amplo onde se articulam mudanças técnicas, organizacionais e institucionais aos níveis mi- 
cro, meso e macroeconômico, salientando os aspectos sociais, econômicos e políticos envolvidos:

"De modo mais geral, o período de 1965 a 1973 tornou cada vez mais evidente a incapacidade do fordismo (formato organizacional predominante associado ao padrão tecnoeconômico vigente na época) e do keynesianismo (forma predominante de intervenção do Estado) de conter as contradições inerentes ao capitalismo. $\mathrm{Na}$ superfície, essas dificuldades podem ser mais bem apreendidas por uma palavra: rigidez. Havia problemas com a rigidez dos investimentos de capital fixo de larga escala e de longo prazo em sistemas de produção em massa que impediam muita flexibilidade de planejamento e presumiam crescimento estável em mercados de consumo invariantes. Havia problemas de rigidez nos mercados, na alocação e nos contratos de trabalho. .... Por trás de toda a rigidez específica de cada área, estava uma configuração indomável e aparentemente fixa de poder político e relações recíprocas que unia o grande trabalho, o grande capital e o grande governo no que pareceria cada vez mais uma defesa disfuncional de interesses escusos definidos de maneira tão estreita que solapavam, em vez de garantir a acumulação do capital” (p. 135-6).

Assim, propõe que a nova ordem mundial seja entendida como:

- resposta encontrada pelo sistema capitalista para o esgotamento de um padrão de acumulação baseado na produção em larga escala de cunho fordista, utilização intensiva de matéria e energia e crescentes problemas ambientais;

- resultado da transição para um regime de acumulação relativamente mais flexível, ou melhor, que se apóia em novas bases, as quais oferecem alternativas e possibilidades de crescimento.

São diversas as contribuições que apontam para esta transição de regime (padrão ou paradigma) de acumulação, a qual se apóia em uma revolução informacional. Tal revolução é vista como engendrando transforma- ções comparáveis àquelas ocorridas em fases anteriores de mudanças radicais no padrão de acumulação capitalista e, em particular, à denominada Revolução Industrial do final do século XVIII. No entanto, nota-se, com freqüência, que os impactos econômicos e sociais esperados da atual ordem mundial em conformação são considerados como até mais importantes que aqueles gerados pela Revolução Industrial, particularmente nos seguintes aspectos:

- "Em termos ideais, a Revolução da Informação repetirá os êxitos da Revolução Industrial. Só que, desta vez, parte do trabalho do cérebro, e não dos músculos, será transferido para as máquinas"2 (p. 46).

- "Este fim de século acena com uma mutação revolucionária para toda a humanidade, só comparável à invenção da ferramenta e da escrita e que ultrapassa largamente a da Revolução Industrial... A Revolução Informacional está em seus primórdios e é primeiramente uma revolução tecnológica que se segue à Revolução Industrial. Mas é também muito mais que isto: constitui o anúncio e a potencialidade de uma nova civilização, pósmercantil, emergente da ultrapassagem de uma divisão entre os que produzem e os que dirigem a sociedade... A transferência para as máquinas de um novo tipo de funções cerebrais abstratas encontra-se no cerne da Revolução Informacional. Tal transferência tem como conseqüência fundamental deslocar o trabalho humano da manipulação para o tratamento da informação"3 (p. 11-3).

Portanto, trata-se - e como resumido por Gomez ${ }^{4}$ - de uma revolução que agrega novas capacidades à inteligência humana e muda o modo de trabaIharmos juntos e vivermos juntos. Informação e conhecimento passam a assumir papel ainda mais visível e estratégico na nova ordem estabelecida, baseando e alavancando as novas possibilidades de crescimento.

\section{Conformação da economia da informação e do conhecimento}

Um aspecto que talvez explique a atenção que autores de diversas áreas vêm conferindo às mudanças discutidas anteriormente e relacionadas à conformação do novo padrão econômicosocial refere-se à constatação do fato exposto a seguir. Como vimos, a partir dos anos 70 e 80, evidenciou-se que o padrão baseado na produção em massa de bens e serviços intensivos em materiais e em energia estava atingindo limites para continuar seu crescimento. Como salientado em diferentes análises, tal padrão começou claramente a denotar problemas de rigidez e esgotamento. Do ponto de vista do padrão produtivo dominante, a alta dos preços do petróleo, a alta generalizada dos preços de várias matériasprimas e as subseqüentes crises com reflexos mundiais, do início daquela década, são tidas como tendo contribuído para expor claramente a vulnerabilidade de um padrão tão dependente de tais insumos.

Novas possibilidades de crescimento foram mais intensamente buscadas a partir de então. Do ponto de vista econômico, dentre as alternativas disponíveis, destacavam-se evidentemente aquelas que apresentavam as meIhores perspectivas para retomada do processo de crescimento. Empresas, governos e demais instituições buscaram explorar várias destas alternativas. Os esforços mais bem-sucedidos foram aqueles que lograram desenvolver e difundir o novo padrão tecnoeconômico baseado na convergência dos avanços realizados nas chamadas Tecnologias de Informação e Comunicação $\left(\right.$ TICs) ${ }^{*}$, e outras das então denominadas tecnologias avançadas (biotecnologia, materiais avançados, química fina e mecânica de precisão).

\footnotetext{
* Este termo inclui as áreas que no jargão brasileiro são mais amplamente conhecidas como informática, telecomunicações, comunicações, ciência da computação, engenharia de sistemas e de software. Interessante é notar que a esperada convergência destas áreas geralmente encontra-se expressa no termo mais curto cunhado em inglês: information technology.
} 
Dentre as possibilidades prometidas na inauguração do novo padrão (muitas das quais ainda estão longe de ser realizadas), destaca-se uma de particular importância para a discussão proposta neste artigo. Esta se relaciona ao já referido fato de (i) a informação e o conhecimento passarem a se constituir nos recursos básicos do crescimento econômico (em lugar dos tradicionais insumos energéticos e materiais) e (ii) tais recursos (nãomateriais e, portanto, intangíveis) não serem esgotáveis. Além disso, o consumo dos mesmos não os destrói, e seu descarte geralmente não deixa vestígios físicos.

Assim, a nova configuração econômica, mais fundamentalmente baseada na informação e no conhecimento, apresenta características extremamente importantes quanto soluções para alguns dos problemas relacionados ao referido esgotamento do padrão anterior, abrindo novas possibilidades de retomada do crescimento, nomeadamente por oferecer formas que possibilitam a continuidade (e até expansão) da produção e consumo em massa de uma série de bens e serviços:

- sem esbarrar nos aspectos relacionados à existência de espaços de armazenamento dos mesmos;

- sem sobrecarregar em ritmo exponencial as demandas de insumos materiais e energéticos;

- sem significar que o descarte - também em massa - de tais bens e serviços* continuará a incrementar o efeito negativo ambiental;

- obtendo maior controle e significativa redução da importância de dois fatores tradicionalmente influentes no custo e valor de todos os bens e serviços produzidos e comercializados no mundo: o tempo e o espaço;

\footnotetext{
* Salienta-se, em particular, a tendência à imaterialidade dos novos bens e serviços, tal como principalmente os softwares de diversos tipos; muitos dos quais podem ser desenvolvidos, produzidos, comprados, distribuídos, consumidos e descartados sem necessariamente depender tanto de uma forma física. E, mesmo nos casos em que existe uma forma física associada aos mesmos, destaque-se o pequeno valor adicionado quanto a tal aspecto e também o fato de estarmos ainda em um momento de transição de padrões e hábitos de consumo.
}

- inaugurando expansão para novo conceito de infra-estrutura, nova dinâmica setorial, novas formas de instituição, organização, produção, comercialização, trabalho, processo de aprendizado, políticas, em suma, novo padrão tecnoeconômico.

Um exemplo refere-se à prometida completa conversão para a forma eletrônica das diferentes formas de informação impressa e gravada (sonora e/ou visual), a qual oferece a possibilidade de utilizar uma quantidade mínima de matéria* e assim reduzir sua alta dependência dos custos associados tanto ao consumo de recursos físicos, quanto a tempo e espaço. Neste caso, nota-se a tendência ao progressivo entrelaçamento dessas diferentes formas de informação e ao barateamento das condições de produção e reprodução das mesmas, produzindo maior avanço relativo das informações sonoras e visuais. Assim, as novas tecnologias da informação permitem hoje, por exemplo, tratar as formas visuais e sonoras quase da mesma maneira que a informação escrita. Se tal tendência vier a se concretizar, isto levará a transformações ainda mais radicais sobre a atual posição relativa da informação escrita no conjunto das diferentes formas da informação. Possivelmente não no sentido de sua superação, mas sim na progressão do entrelaçamento entre todas as formas.

Propõe-se avançar em tal discussão, analisando, primeiramente, uma exigência mais básica associada ao advento e difusão da economia da informação e do conhecimento, qual seja, a pressão para o aprofundamento das formas econômicas (e outras correla-

\footnotetext{
* $E$, ao mesmo tempo, de poupar imensamente o consumo de meios energéticos. Um dos mais aludidos exemplos neste caso refere-se à perspectiva de passarmos crescentemente a produzir, tratar, disseminar e consumir estes tipos de informação na forma eletrônica; e, apenas se, quando e quanto necessário materializá-los. Futurólogos estão sempre a lembrar-nos que, daqui há alguns anos, talvez não estaremos mais a acumular, por exemplo, impressos (de todo o tipo), discos e vídeos em nossos ambientes de trabalho ou residências; faremos simplesmente um download daquela informação que, naquele momento, desejamos, sem que necessariamente utilizemos formas materiais para veiculá-la.
}

tas como jurídicas etc.) de privatizar estes recursos, conferir valor, assim como garantir a propriedade dos mesmos. As atuais exigências dizem respeito também às formas de definir, regular, cobrar, taxar e orientar a produção, tratamento e disseminação dos mesmos. Uma alegada dificuldade para tal refere-se ao reconhecimento que tais recursos, conforme visto anteriormente, ao contrário dos tradicionais, são regidos por diversas leis que tomam pelo avesso os conceitos e raciocínios econômicos clássicos ${ }^{\star}$ :

- informação e conhecimento são recursos intangíveis, não-materiais e, portanto, não esgotáveis. Seu consumo não os destrói, assim como seu descarte geralmente não deixa vestígios físicos. Cedê-los (mediante venda, por exemplo) não faz com que sejam perdidos;

- os novos bens e serviços (como, por exemplo, um novo software), uma vez produzidos ou criados, podem ser reproduzidos a custos quase que irrelevantes;

Nota-se, no entanto, que pressões para readaptação de tal tipo fazem-se sentir particularmente nas épocas de mudanças tecnoeconômicas radicais, as quais acompanham a evolução da humanidade e que resultaram em uma série de outras transformações, inclusive jurídicas e legais. Assim é que, em geral, atualmente, aceita-se a privatização e reconhece-se a propriedade (assim como os correlatos sistemas de preços e normas jurídicas para utilização) de diversos bens que, em outras épocas, já foram considerados como públicos: a terra, água, os recursos minerais e até a informação e o conhecimento.

Nesta discussão, destaca-se a maior dificuldade relativa do sistema jurídico e econômico em delimitar, reconhecer e garantir a propriedade de recursos intangíveis. No entanto, nota-se que o desenvolvimento de meios de privatizar algumas formas de conhecimento mais importantes para o sistema econômico, como a tecnologia, começaram a ser desenvolvidas há muitos anos $^{* *}$.

\footnotetext{
* Ver Levy ${ }^{5}$ e Baptista ${ }^{12}$.

** Ver, por exemplo, o desenvolvimento do sistema de patentes e propriedade intelectual.
} 
Adicionalmente e no que se refere às maneiras de conferir preço e cobrar os novos bens e serviços produzidos e ofertados no mercado, nota-se o desenvolvimento de meios tão revolucionários quanto os próprios. Como exemplo, cita-se o já mundialmente difundido formato de cobrar os serviços fornecidos particularmente (mas não exclusivamente) pelos meios de comunicação. Como no caso do telespectador que - ao assistir a programas de televisão nos chamados canais abertos - não paga os serviços que utiliza através das formas (anteriormente) consideradas tradicionais, ou seja, utilizando dinheiro ou outro equivalente; mas sim pela exposição de sua atenção às informações publicitárias veiculadas por esse meio.

As novas formas de pagamento desses serviços, por não envolverem trocas físicas diretas, são em muitos casos imperceptíveis até mesmo para grande parte dos indivíduos que os consomem. Alguns serviços disponibilizados pela Internet (muitos dos quais anunciados como grátis) já vêm utilizando forma semelhante de cobrança, podendo-se prever o possível alargamento e maior sofisticação deste meio de pagamento paralelamente à difusão do novo paradigma das tecnologias da informação e comunicações e atividades associadas. Assim, ressalta-se que quanto mais velozmente se acelera e aprofunda o processo de mudança, mais claramente destaca-se a importância das referidas adaptações. Levy ${ }^{5}$ é um dos que também vêm salientando tal aspecto: "Estamos diante da necessidade de dar um salto ... porém ainda não dispomos de qualquer sistema de medição, de qualquer contabilidade, representação, regulamentação jurídica digna deste nome, embora as mesmas estejam na origem de todas as formas contemporâneas de poder" (p. 87).
Conforme já destacado, a transição de um modelo baseado em produtos materiais industriais para outro, baseado nos serviços e em produtos imateriais (Sant'Anna*) consiste em um dos aspectos mais importantes oferecidos pelo novo modo de acumulação capitalista. Isto incluindo as possibilidades relacionadas às novas formas de teletrabalho, telereuniões, telecomércio e sem falar naquelas concernentes aos diferentes usos da realidade virtual, tais como nas escolas virtuais, programas virtuais, cirurgias virtuais $^{7}$.

Assim, processos de $\mathrm{P} \& \mathrm{D}$, produtivos e outros, já em franca difusão particularmente nas economias capitalistas mais avançadas, deixam de apoiar-se tanto em bases e bens materiais industriais em favor das atividades relacionadas aos serviços e, particularmente, aquelas atividades mais intensivas em informação e em conhecimento**.

Informação e conhecimento, ao assumir papel ainda mais importante e estratégico na nova ordem econômica estabelecida, transformam-se em fontes de maior produtividade e de crescimento econômico. Tal tendência geralmente é exemplificada por meio de indicadores sobre a participação dessas últimas atividades no Produto Nacional Bruto (PNB) e proporção da população empregada em tais atividades nos referidos países. Conforme apontado por diferentes autores, já em 1990 , mais de $40 \%$ da população empregada nos países mais avançados desenvolviam atividades intensivas em informação ${ }^{6}$.

\footnotetext{
* Este autor discute as novas formas de se mensurar e classificar o setor de serviços (o qual passa a constituir-se no mais dinâmico do novo padrão); oferecendo também interessante resenha das dificuldades que, na história do pensamento econômico, diferentes autores manifestaram ao se deparar com o problema de tratar deste setor geralmente considerado como improdutivo, particularmente devido à sua imaterialidade e, portanto, invisibilidade ${ }^{6}$.

** Tal percepção é que teria levado alguns autores a desenvolver a noção de uma transição da economia mundial (até então muito centrada em atividades industriais) para uma nova fase - supostamente pós-industrial - baseada grandemente na dinâmica do setor de serviços.
}

Nesta discussão, ressalta-se também que a parcela considerada "invisível" da dinâmica econômica vem aumentando em importância ao longo dos anos. Tal fato tem particular importância nos tempos atuais quando os denominados produtos e serviços intermediários de informação representam uma parcela bem maior da economia, abrangendo, por exemplo, todas as tarefas administrativas que dão base à produção de todos os bens e serviços finais. Reflexões deste tipo é que já têm levado, há algum tempo, à conclusão de que realmente vivemos uma nova era histórica em que a economia está mais direta e fortemente enraizada na produção, tratamento, distribuição e uso da informação e do conhecimento.

Apontam-se ainda como importantes características correlacionadas desta era:

- a exploração mais intensa da dimensão informacional do espaço, a qual vem apresentando progressivo crescimento particular, mas não exclusivamente, na esfera econômica. Com o objetivo de analisar tal dimensão, uma série de designações e conceitos tem sido desenvolvida. Dentre estes, destacam-se o ciberespaço ${ }^{5}$, o espaço dos fluxos ${ }^{8}$ e o espaço informacional ${ }^{9}$.

- a inauguração de uma nova forma de infra-estrutura que sustenta o novo modo de produção. Neste último caso, ressalta-se, inclusive, o uso da expressão "rodovias ou auto-estradas da informação" distinta (apesar de emprestada) da tradicional infra-estrutura de transporte que baseou, deste seu advento, os modelos de produção de bens materiais, desde os extrativos (agrícolas e minerais) até as formas mais sofisticadas de produtos industriais. Do mesmo modo que o vertiginoso aumento da produção de bens possibilitado pela revolução industrial exigiu nova infra-estrutura de transporte condizente, as atuais infovias são vistas como resposta ao, também vertiginoso, aumento da produção e fluxo de informação ${ }^{10}$. 


\section{As novas estratégias e formatos organizacionais da economia da informação e do conhecimento}

Como uma conseqüência das transformações discutidas anteriormente, reforçou-se o papel da gestão estratégica da informação econômica e do conhecimento como ferramenta fundamental para o crescimento econômico. Conforme, por exemplo, apontado por Passos ${ }^{11}$, o desenho de sistemas de inteligência econômica (ou inteligência competitiva) - tanto ao nível privado quanto público, global ou localizado - ganharam destaque ainda maior nas estratégias de diferentes instituições. Tais sistemas procuram equacionar a necessidade de se promover também a geração de conhecimentos que permitam utilizar as informações disponibilizadas, por meio de estratégias que se auto-alimentam. Novos modelos de gestão são desenvolvidos tanto aos níveis das esferas da pesquisa e desenvolvimento, produção e comercialização de bens e serviços, quanto das esferas de planejamento estratégico. Tais processos privilegiam a agilidade na tomada de decisões e na incorporação de mudanças e visam a adaptar as organizações à nova realidade ${ }^{7,11,13}$.

Como outra marcante característica associada a esta transição, as empresas e demais instituições vêm reestruturando suas funções e atividades, assim como vêm definindo e implementando novas estratégias de atuação, desenvolvendo e adotando novos desenhos organizacionais, novos instrumentos e metodologias operacionais. Esses novos formatos organizacionais enfatizam a descentralização, a terceirização e a interação interna e com parceiros de todos os tipos. Tais formatos - apoiando-se e beneficiando-se dos meios técnicos atualmente disponíveis para veiculá-los - igualmente baseiam-se crescentemente em informação e conhecimento.
Portanto, não é de espantar o exponencial desenvolvimento e difusão de redes de diferentes tipos e formas reunindo atores espalhados pelo mundo inteiro*. Neste caso, salienta-se especialmente que: (i) a constituição de redes é considerada como a mais importante inovação organizacional associada à difusão do novo paradigma tecnoeconômico das tecnologias da informação; (ii) a competitividade das organizações passa a estar relacionada à abrangência das redes em que estão inseridas, assim como a intensidade do uso que fazem das mes$\operatorname{mas}^{12,13}$.

Assim é que autores, como Castells, ${ }^{8}$ vêm inclusive denominando a nova ordem como sociedade rede (network society): resultante da revolução das tecnologias da informação e da reestruturação do capitalismo. A nova ordem é então caracterizada pelo formato organizacional interativo pela transformação das bases materiais da vida, do espaço e tempo, bem como pela cultura da realidade virtual construída por um sistema de mídia pervasivo, interconectado e diversificado.

Adicionalmente e tendo em vista as características específicas do novo padrão baseado nas TICs, aponta-se para a intensificação da complexidade dos novos processos produtivos e para a aceleração dos novos desenvolvimentos, implicando uma taxa de mudança mais rápida tanto em processos quanto em bens e serviços. Portanto, além de conter um componente importante e transitório de ajuste às novas exigências, o padrão atualmente em difusão implica maior necessidade de capacitação e, ao mesmo tempo, vem exigindo dinâmica recapacitação para que os indivíduos e instituições mantenham-se constantemente atualizados ${ }^{14}$.

\footnotetext{
* Como ressalta Gomez ${ }^{4}$, alimentada por um fluxo incessante de informações, a empresarede deixa suas estruturas verticais e centralizadas para adotar contornos flutuantes. Como é testemunhado, por exemplo, pelo recurso à terceirização; por sua vez, essas empresas têm a possibilidade de contratar serviços e produtos a outras. A rede se transforma e se regenera constantemente.
}

Nesta discussão, ressalta-se que, para que um determinado país, instituição ou indivíduo possa identificar e implementar, com sucesso, as informações que gera e monitora, não basta uma estrutura moderna, sofisticada, flexível e um excelente sistema de informações. Mostra-se primordial contar com uma base de conhecimentos que envolva um processo de aprendizado contínuo. Assim, em face dos novos desafios apresentados e reconhecendo a necessidade de investir constantemente em inovação, passam a ter relevo ainda maior os objetivos de promover e gerar processos que estimulem o aprendizado e a acumulação de conhecimentos. Neste sentido e como principalmente (mas não exclusivamente) as análises de autores das áreas de negócios e administração indicam, verifica-se maior preocupação das empresas e outras organizações com as novas exigências de capacitação de recursos humanos.

Nesta linha, advoga-se, como nos lembra Arruda $^{7}$, que, na era virtual, quando a desmaterialização encontrase no cerne da nova dinâmica econômica, as estratégias competitivas sustentáveis passam a cultuar não tanto o parque industrial e os tradicionais insumos produtivos, mas sobretudo o potencial humano especializado e sua capacitação, como fator de agregação real de valor duradouro às organizações, e, assim, aos bens e serviços que produzem. Em tal quadro, o investimento na capacitação e na atualização de funcionários deixa de ser visto como uma despesa e passa a ser visto como uma forma de agregar valor à organização e formar o capital humano que vai transformar o conhecimento produzido dentro e fora da organização em conhecimento produtivo/competitivo, contribuindo assim para a transformação da mesma em uma organização voltada para o aprendizado e para o conhecimento.

Seguindo linha semelhante, alguns autores vêm argumentando que as empresas japonesas tornaram-se extremamente bem-sucedidas no cenário competitivo dos anos 70 e 80 , devido à capacidade das mesmas em captar informações estratégicas e criar novos conhecimentos exploran- 
do ao máximo os processos de interconexão e colaboração como base do aprendizado. Neste sentido, antepõem: (i) as bases tradicionais do que consideram como "filosofia competitiva das organizações ocidentais" ênfase no indivíduo como agente principal da acumulação de conhecimentos; (ii) o desenvolvimento e adoção de práticas eficientes de "criação de conhecimentos em nível das organizações" (organizational knowledge creation). A partir das análises das características básicas da capacidade das empresas japonesas em fazer uso dos formatos organizacionais interativos que objetivam estimular os processos para criação de novos conhecimentos coletivamente, Nonaka e Takeuchi ${ }^{14}$ propõem as bases de uma nova teoria da criação e gestão de conhecimentos em organizações.

Como destacado, por exemplo, por Cassiolato ${ }^{15}$, as atuais mudanças contribuem para a transformação da economia no sentido de colocar o conhecimento como o recurso mais estratégico e o aprendizado como o processo mais importante. Devido particularmente a essas novas exigências e ao papel desempenhado pelo conhecimento e pelo aprendizado no dinamismo do novo padrão, é que alguns autores vêm inclusive preferindo denominar a atual fase de Economia do Conhecimento ou do Aprendizado.

Tal ressalva mostra-se ainda mais importante quando se consideram os riscos associados à grande virada da informação impressa para a eletrônica e à conseqüente possibilidade de hiperinformação resultante do maior volume de informação produzida e em circulação. Além disso e como apontam Aun ${ }^{16}$ e Arruda ${ }^{7}$, entre os mais discutidos desafios associados à economia da informação, inclui-se o problema relacionado à pobreza de informações substanciosas em conteúdo em face da enorme quantidade de informações insignificantes difundidas* .

\footnotetext{
* Autores como VIRILIO, 1996, advertem inclusive quanto aos riscos da denominada poluição informacional, considerados ainda mais complexos e sérios do que aqueles advindos das formas tradicionais de poluição, uma vez que afeta um órgão vital do corpo humano: o cérebro.
}

A premência em equacionar tais questões evidencia-se ainda mais quando lembramos, como nos recomenda Albagli ${ }^{17}$ que o controle de informações e conhecimentos - particularmente aqueles mais estratégicos - tende a definir, cada vez mais, a posição relativa dos países no cenário internacional, assim como dos diferentes segmentos sociais dentro de cada país.

\section{CONSIDERAÇÕES FINAIS}

A literatura disponível sobre a Economia da Informação e do Conhecimento tem salientado que importantes mudanças já estão em curso. Tais transformações são vistas como implicando importantes readaptações e reestruturações, afetando, entre outros: (i) setores produtivos; (ii) instituições transnacionais e nacionais, públicas e privadas, suas formas de organização, assim como suas estratégias e políticas; (iii) indivíduos, uma vez que novas bases de conhecimento e capacitação passam a ser exigidas no novo cenário.

Faz-se necessário identificá-las e entendê-las, ainda em tempo de contribuir para orientar seus desenvolvimentos. Neste sentido, propõe-se terminar este artigo resgatando uma consideração final derivada da discussão realizada anteriormente: em uma época em que a importância do conhecimento mostra-se ainda maior e suas características de cumulatividade e interatividade mostram-se ainda mais salientes - aponta-se para a necessidade de:

- superar as atuais fronteiras do conhecimento disponível para sua própria análise, visando a minimizar as dificuldades inerentes à compreensão das atuais transformações;
- compreender que, ao invés de antagônicos (ou rivais), os diferentes pontos de vista e bagagens teórico-conceituais sobre temas como os abordados anteriormente podem oferecer a complementaridade necessária ao melhor entendimento dos mesmos;

- maximizar a sinergia que enfoques multidisciplinares podem produzir em termos de alcance e profundidade no processo de geração do conhecimentos nas áreas humanas e sociais, da mesma forma que nas chamadas áreas exatas. Alude aqui particularmente a anteriormente referida convergência de conhecimento nas áreas de computação, eletrônica, sistemas, comunicações, etc., a qual forma a base técnica das atuais transformações. 


\section{REFERÊNCIAS BIBLIOGRÁFICAS}

1. HARVEY, D. Condição Pós-Moderna, (Edições Loyola, São Paulo, 1996).

2. DERTOUZOS, M. O Que Será: como o mundo da informação transformará nossas vidas, (Cia das Letras, São Paulo, 1997)

3. LOJKINE, J. A Revolução Informacional (Editora Cortez, 1995).

4. GOMEZ, M. N. G. "A Globalização e os Novos Espaços da Informação", Informare, vol. 3, ํㅜ1-2, (PPCI/IBICT, Rio de Janeiro, 1997).

5. LEVY, P. A Inteligência Coletiva, (Instituto Piaget, Lisboa, 1997).

6. SANT'ANNA, R. N. 'O Setor de Serviço na Sociedade da Informação: contribuições para a montagem de um sistema de informações estatísticas', Dissertação de Mestrado, PPCI - UFRJ/CNPq/IBICT (Rio de Janeiro, 1998).

7. ARRUDA, M. C. C. "Revolução Informacional, Globalização e as Mudanças na Capacitação Profissional" , Informare, vol. 3, o1-2, (PPCI/IBICT, Rio de Janeiro, 1997).

8. CASTELLS, M. The Information Age: economy, society and culture, (Blackwell, Oxford, 1997).

9. VIRILIO, P. A Arte do Motor, (Estação Liberdade, São Paulo, 1996).
10. FREEMAN, C. "Information Highways and Social Change", mimeo (IDRC, Canada, 1995).

11. PASSOS, C. K. "O Novo Paradigma Produtivo e as Informações", Informare, vol. 3, no1-2, (PPCI/IBICT, Rio de Janeiro, 1997).

12. BAPTISTA, R. F. "Os Novos Paradigmas da Sociedade da Informação e os Modelos de Pólos e Parques Científicos e Tecnológicos", Informare, vol. 3, nㅜ1-2, (PPCI/IBICT, Rio de Janeiro, 1997).

13. LEMOS, C. R. "Redes Locais de Informação para Inovação Face à Globalização"

14. NONAKA, I. e TAKEUCHI, H. The Knowledge Creating Company, (Oxford University Press, Oxford 1995) tradução para o português publicada em 1997.

15. CASSIOLATO, J. E. "Globalização e Tecnologias da Informação e Comunicações: A Importância das Políticas Públicas", Informare, vol. 3, no 1-2, (PPCl/ IBICT, Rio de Janeiro, 1997).

16. AUN, M. P. "Processo de Globalização e Políticas Nacionais de Informação", Informare, vol. 3, no 1-2, (PPCl/IBICT, Rio de Janeiro, 1997).

17. ALBAGLI, S. "Informação e Geopolítica Contemporânea: o papel dos sistemas de propriedade intelectual", Informare, vol. 3, no 1-2, (PPCl/IBICT, Rio de Janeiro, 1997).

\section{Information and knowledge in the new world order}

\begin{abstract}
This article discusses the role of information and knowledge in the new world order. The main focus is on the advent and diffusion of the so-called Information and Knowledge Economy which is inducing new activities, concepts of competitiveness, strategies and institutional formats, as well as requiring new skills.
\end{abstract}

\section{Keywords}

Information and knowledge economy; Information and communication technology; Information and competitiveness strategies.

\section{Helena M. M. Lastres}

Ph.D. em ciência, tecnologia e industrialização, SPRU/University of Sussex, mestre em Engenharia da Produção, Coppe/UFRJ e economista FEA/UFRJ. Professora e pesquisadora do Programa de Pós-Graduação em Ciência da Informação, PPCI/UFRJ (Convênio CNPq/IBICT-UFRJ/ECO).

e-mail hlastres@ie.ufrj.br ou hlastres@excite.com.br. 